\title{
A six-chambered heart: cor triatriatum sinister with double-chambered right ventricle in association with ventricular septal defect
}

\author{
Vivek Jaswal ${ }^{1}$, Pratyaksha Rana ${ }^{2}$, Vidur Bansal ${ }^{*}$ (ID, Krishna Prasad Gourav ${ }^{3}$, Arun Sharma ${ }^{2}$ and \\ Shyam Kumar Singh Thingnam
}

\begin{abstract}
Background: Cor triatriatum has been described as a heart with three atria in which the left atrium (cor triatriatum sinistrum) or right atrium (cor triatriatum dextrum) is divided into two compartments by a fold of tissue, a membrane, or a fibromuscular band. Double-chambered right ventricle, on the other hand, is identified by the presence of an anomalous muscle bundle dividing the right ventricle into two chambers.

Case presentation: Here, we describe the case of a child who had a combination of both of these rare entities, effectively creating a heart with six chambers. The child underwent a successful intracardiac repair.

Conclusions: The association of CTS with DCRV forming a "6-chambered heart" is extremely rare. Awareness of its existence and accurate preoperative diagnosis has important implications in its surgical repair with all the components of this disease spectrum, further increasing the complexity of a successful surgical repair.
\end{abstract}

Keywords: Cor triatriatum, Double, Right ventricle, Left vena cava

\section{Background}

In cor triatriatum sinister (CTS), the proximal chamber of the left atrium (LA) receives venous blood, whereas the distal chamber is in contact with the atrioventricular valve and contains the atrial appendage and the true atrial septum bearing the fossa ovalis. The membrane that separates the atrium into two parts varies significantly in size and shape. In double-chambered right ventricle (DCRV), an anomalous muscle band divides the right ventricular cavity into a proximal and a distal chamber [1]. In the pediatric population, CTS may be associated with major congenital cardiac lesions but its association with DCRV has not been described thus far in the literature.

\footnotetext{
*Correspondence: vidurbansal05@gmail.com

${ }^{1}$ Department of Cardiothoracic and Vascular Surgery, Post Graduate Institute of Medical Education and Research, Chandigarh 160012, India Full list of author information is available at the end of the article
}

\section{Case presentation}

A 2-year-old child is presented with the complaints of shortness of breath while playing and moderate cyanosis for the past one and a half years. The symptoms had progressed over the past 3 months. On examination, the child had an oxygen saturation of $80 \%$ on room air and a systolic murmur in the pulmonary area.

The child was further evaluated with basic investigations and a transthoracic echocardiography, which revealed CTS in association with DCRV, having a gradient of $70 \mathrm{mmHg}$ across it, a perimembranous ventricular septal defect (VSD) in the proximal chamber of right ventricle, a small atrial septal defect (ASD) between the right atrium (RA) and distal chamber of the LA in the septum secundum and persistent left superior vena cava (PLSVC) (Fig. 1). The atrial membrane that separated the proximal and distal chambers of LA, was mildly restrictive with a mean gradient of $4 \mathrm{mmHg}$ across it. The coronary sinus was dilated. 


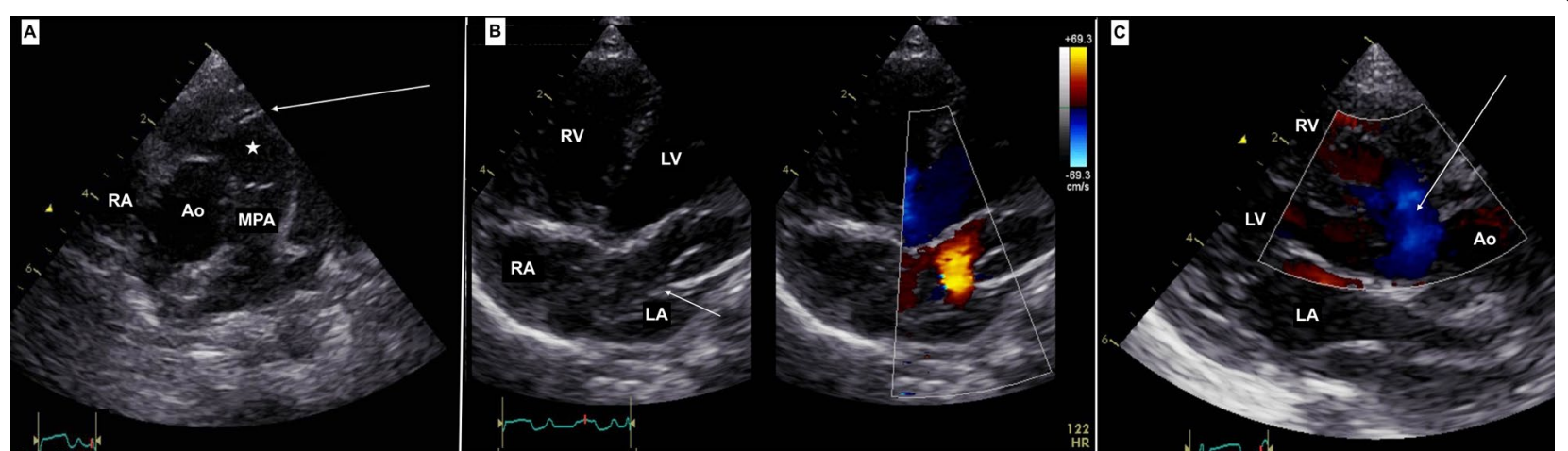

Fig. 1 Transthoracic echocardiography. A Parasternal short axis view showing the hypertrophied muscle bands (arrow) with distal infundibular chamber $(*)$. B Apical four-chamber view showing the membranous partition in the LA (arrow) with turbulent flow across its aperture. C Parasternal long axis view showing the perimembranous VSD (arrow). (Ao-aorta)

Computed tomography (CT) angiography confirmed the above findings (Fig. 2). The child was then planned for a definitive intracardiac repair. After a median sternotomy, the surface anatomy of the heart was assessed. Invasive pressure monitoring showed RV systolic pressures $(89 \mathrm{mmHg})$ almost equal to the systemic systolic pressure $(91 \mathrm{mmHg})$. Cardiopulmonary bypass (CPB) was instituted with cannulation of the ascending aorta, right superior vena cava (RSVC), LSVC and inferior vena cava (IVC). The heart was arrested in diastole with Del Nido cardioplegia. Patient was cooled to $34{ }^{\circ} \mathrm{C}$ and the RA was opened. Through the ASD, the distal chamber of the LA in contact with the mitral valve was entered. A small opening between the proximal and distal chambers of the LA was visualized. The membranous partition (Fig. 3A) adjoining this small opening was excised taking care not to injure the wall of the dilated coronary sinus (DCS) (Fig. 3B) and the underlying mitral valve. The fibrotic os infundibulum and hypertrophied obstructing parietal and septal muscle bands were excised facilitating an Hegar's dilator that was appropriately sized according to the Rowlatt chart. The VSD and ASD were closed using an autologous $0.6 \%$ glutaraldehyde treated pericardial patch. The child was successfully weaned off $\mathrm{CPB}$. Invasive pressure monitoring showed RV pressures of $33 / 1 \mathrm{mmHg}$ and LV pressures of $75 / 30 \mathrm{mmHg}$. Thus, postoperatively, the RV systolic pressures were reduced to $40 \%$ of the systemic systolic pressures. The child was shifted to the ICU on ionotropic support. The child was extubated on first postoperative day but subsequently developed superficial surgical site infection. The child was discharged on 12th postoperative day and is currently doing well in follow-up.

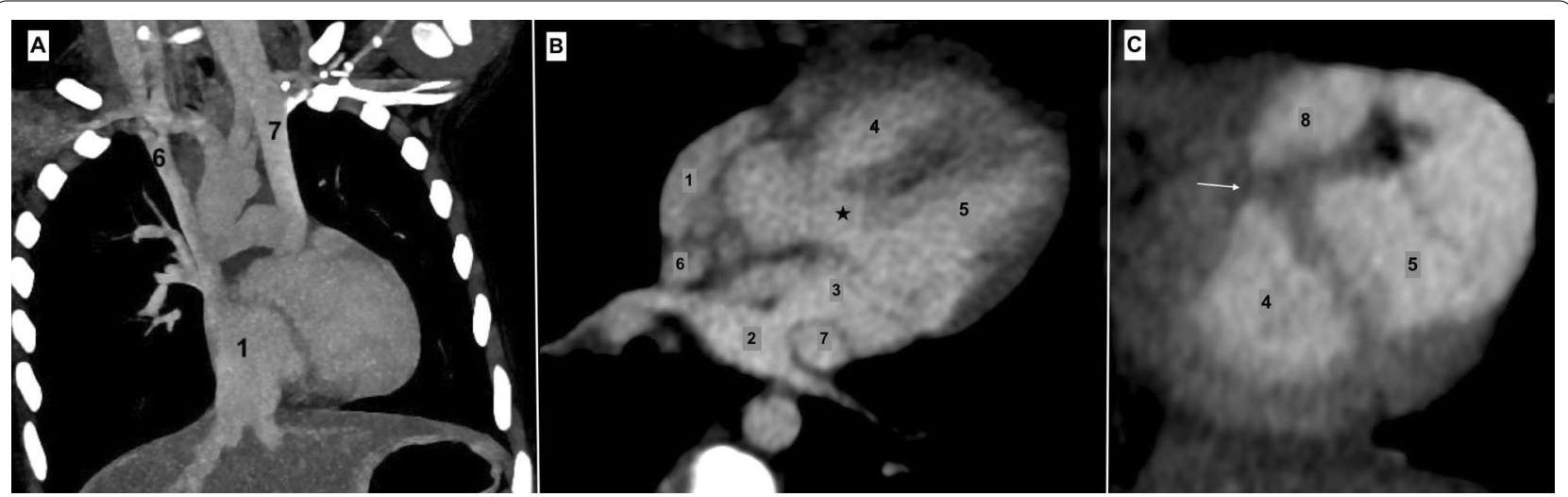

Fig. 2 CT Angiography. A Coronal section showing double SVC draining into RA. B Four-chamber view showing cor triatriatum, VSD (*) and double SVC. C Two-chamber view showing the infundibular chamber and the hypertrophied obstructing muscle bands (arrow) dividing the RV into two chambers. 1-Right atrium, 2-posterior chamber of left atrium, 3-anterior chamber of left atrium, 4-right ventricle, 5-left ventricle, 6-right superior vena cava, 7-left superior vena cava, 8-infundibular chamber 


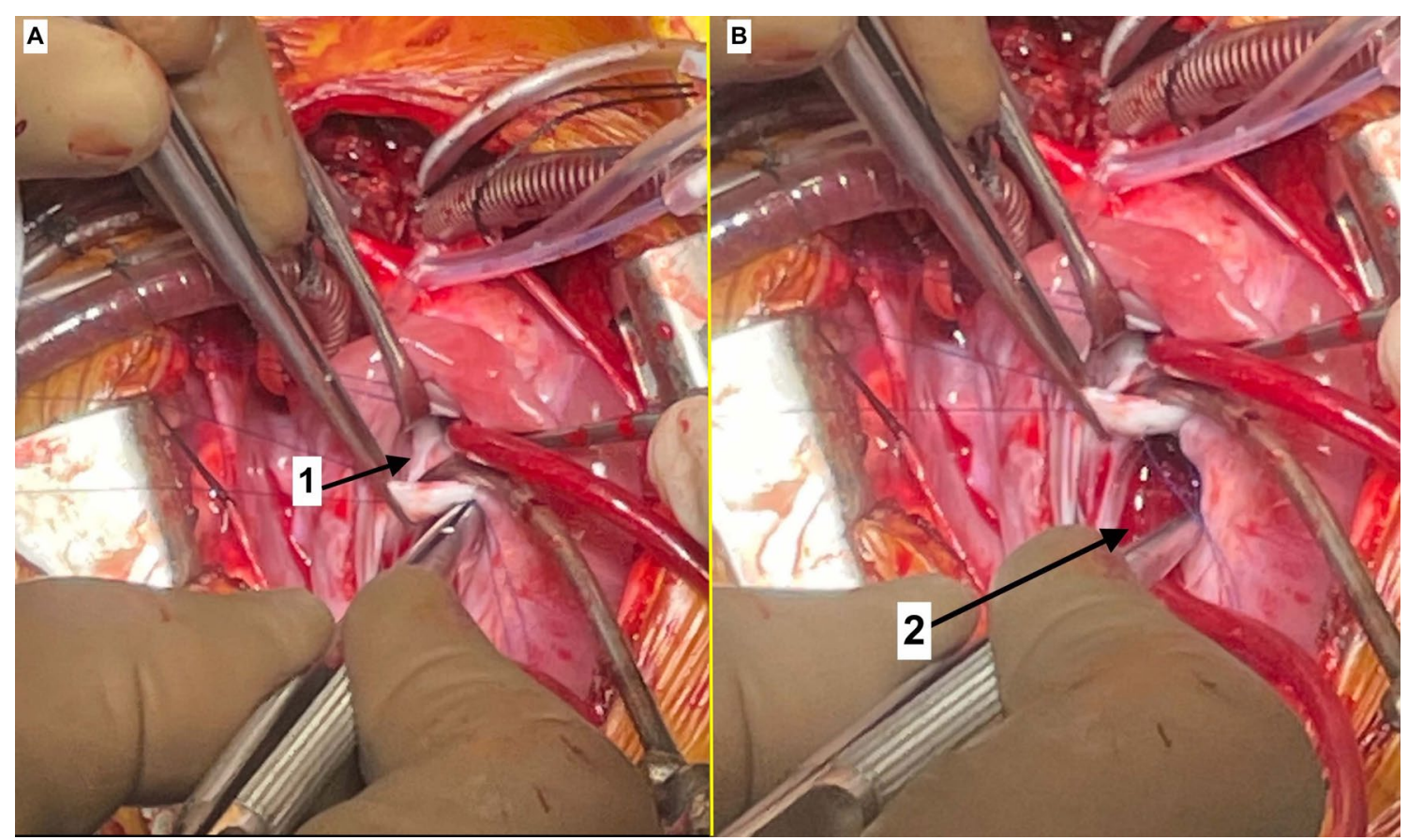

Fig. 3 Intra-operative images. A The membranous partition (1) of LA as seen through the PFO. B The dilated coronary sinus (2)

\section{Discussion}

The incidence of cor triatriatum has been variously reported as $0.1-0.4 \%$ [2]. Patients with CTS are present with symptoms similar to mitral stenosis. These patients usually have pulmonary hypertension and signs of RV failure [3]. PLSVC is present in $0.5 \%$ of the general population and results from failure of occlusion of the left cardinal vein in embryonic life [4]. It drains into the right atrium through the coronary sinus in most cases and a DCS on imaging should raise suspicion of its presence. A DCS can have implications in repair of such a lesion as the inter-atrial septum can only be excised to a limited extent to gain entry into the left atrium. Further, a DCS can complicate excision of the membranous partition in the LA as the roof of a DCS can be mistaken for the LA membrane.

A VSD may communicate with either the proximal or distal chamber, leading to a greater shunt in the latter situation. Development of RV outflow tract obstruction occurs in 3-7\% of patients with membranous VSD's within the first year of life $[5,6]$.

CTS is amenable to surgical correction with excellent results when diagnosed. Long-standing inflow obstruction to the left ventricle leads to pulmonary venous and arterial hypertension along with right ventricular dysfunction. Additional presence of DCRV along with CTS adds to the complexity as it leads to further RV hypertrophy, exposes the RV to pressure overload and increases the predisposition to early RV dysfunction. Hence, the need for early surgical intervention in such cases. In our case, the six chambers of the heart were correctly diagnosed by preoperative echocardiography and CT-angiogram, facilitating the surgical planning beforehand. A six-chambered heart as described here was described around 50 years back but the morphology was entirely different [7].

\section{Conclusions}

The association of CTS with DCRV forming a "6-chambered heart" is extremely rare. Awareness of its existence and accurate preoperative diagnosis has important implications in its surgical repair with all the components of this disease spectrum further increasing the complexity of successful surgical repair.

\section{Abbreviations}

ASD: Atrial septal defect; CTS: Cor triatriatum sinistrum; CPB: Cardiopulmonary bypass; DCRV: Double-chambered right ventricle; DCS: Dilated coronary sinus; LA: Left atrium; LV: Left ventricle; PLSVC: Persistent left superior vena cava; RA: Right atrium; RV: Right ventricle;VSD: Ventricular septal defect.

\section{Acknowledgements}

Not applicable.

\section{Authors' contributions}

VJ involved in manuscript editing; PR involved in manuscript writing; VB involved in manuscript writing; KPG involved in manuscript editing; AS involved in manuscript editing; SKST involved in manuscript editing. All authors read and approved the final manuscript. 


\section{Funding}

No funds were received for this work.

\section{Availability of data and materials}

Yes.

\section{Declarations}

Ethics approval and consent to participate

Not applicable. Informed consent was taken from the child's parents to publish this case report.

\section{Competing interests}

There is no competing interests of any author (s).

\section{Author details}

'Department of Cardiothoracic and Vascular Surgery, Post Graduate Institute of Medical Education and Research, Chandigarh 160012, India. ${ }^{2}$ Department of Radiodiagnosis and Imaging, Post Graduate Institute of Medical Education and Research, Chandigarh, India. ${ }^{3}$ Department of Anesthesia, Post Graduate Institute of Medical Education and Research, Chandigarh, India.

Received: 6 January 2022 Accepted: 6 February 2022

Published online: 16 February 2022

\section{References}

1. Loukas M, Housman B, Blaak C et al (2013) Double-chambered right ventricle: a review. Cardiovasc Pathol 22:417-423

2. Thakrar A, Shapiro MD, Jassal DS et al (2007) Cor triatriatum: the utility of cardiovascular imaging. Can J Cardiol 23:143-145

3. Saxena P, Burkhart HM, Schaff HV et al (2014) Surgical repair of cor triatriatum sinister: the Mayo Clinic 50-year experience. Ann Thorac Surg 97:1659-1663

4. Perles Z, Nir A, Gavri S et al (2013) Prevalence of persistent superior vena cava and association with congenital heart anomalies. Am J Cardiol 112:1214-1218

5. Hubail ZJ, Ramaciotti C (2007) Spatial relationship between the ventricular septal defect and the anomalous muscle bundle in a double-chambered right ventricle. Congenit Heart Dis 2:421-423

6. Pongiglione G, Freedom RM, Cook D, Rowe RD (1982) Mechanism of acquired right ventricular out ow tract obstruction in patients with ventricular septal defect: an angiocardiographic study. Am J Cardiol 50:776-780

7. Paredes S, Berger RL, Gardner T, Hipona FA (1971) A six chambered heart: biventricular outlet obstruction in association with interventricular septal defect. Am J Roentgenol Radium Ther Nucl Med 111:771-775

\section{Publisher's Note}

Springer Nature remains neutral with regard to jurisdictional claims in published maps and institutional affiliations.

\section{Submit your manuscript to a SpringerOpen ${ }^{\circ}$ journal and benefit from:}

- Convenient online submission

- Rigorous peer review

- Open access: articles freely available online

- High visibility within the field

- Retaining the copyright to your article 